Facilitation of Third-party Development of Advanced Algorithms for Explosive Detection Using Workshops and Grand Challenges

H. E. Martz, C. R. Crawford, J. S. Beaty, D. Castanon

February 24, 2011

The DSH Science Conference - Fith Annual University Network Summit Washington, WA, United States March 30, 2011 through April 1, 2011 
This document was prepared as an account of work sponsored by an agency of the United States government. Neither the United States government nor Lawrence Livermore National Security, LLC, nor any of their employees makes any warranty, expressed or implied, or assumes any legal liability or responsibility for the accuracy, completeness, or usefulness of any information, apparatus, product, or process disclosed, or represents that its use would not infringe privately owned rights. Reference herein to any specific commercial product, process, or service by trade name, trademark, manufacturer, or otherwise does not necessarily constitute or imply its endorsement, recommendation, or favoring by the United States government or Lawrence Livermore National Security, LLC. The views and opinions of authors expressed herein do not necessarily state or reflect those of the United States government or Lawrence Livermore National Security, LLC, and shall not be used for advertising or product endorsement purposes. 


\title{
Facilitation of Third-party Development of Advanced Algorithms for Explosive Detection Using Workshops and Grand Challenges
}

\author{
Harry E. Martz ${ }^{1}$, Carl R. Crawford ${ }^{2}$, John S. Beaty ${ }^{2}$, and \\ David A. Canstañón ${ }^{2}$ \\ ${ }^{1}$ Lawrence Livermore National Laboratory \\ Livermore, CA \\ ${ }^{2}$ Explosives Division, Science \& Technology Directorate \\ US Department of Homeland Security \\ Washington, DC \\ Work performed on the \\ Science \& Technology Directorate of the \\ Department of Homeland Security \\ Statement of Work \\ PR RSEN-08-00066
}

February 13, 2011

IM 470131

LLNL-CONF-471533

This work performed under the auspices of the U.S. Department of Energy by Lawrence Livermore National Laboratory under Contract DE-AC52-07NA27344. 


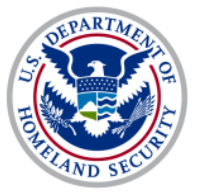

\section{Disclaimer}

This document was prepared as an account of work sponsored by an agency of the United States government. Neither the United States government nor Lawrence Livermore National Security, LLC, nor any of their employees makes any warranty, expressed or implied, or assumes any legal liability or responsibility for the accuracy, completeness, or usefulness of any information, apparatus, product, or process disclosed, or represents that its use would not infringe privately owned rights. Reference herein to any specific commercial product, process, or service by trade name, trademark, manufacturer, or otherwise does not necessarily constitute or imply its endorsement, recommendation, or favoring by the United States government or Lawrence Livermore National Security, LLC. The views and opinions of authors expressed herein do not necessarily state or reflect those of the United States government or Lawrence Livermore National Security, LLC, and shall not be used for advertising or product endorsement purposes.

\section{Auspices Statement}

This work performed under the auspices of the U.S. Department of Energy by Lawrence Livermore National Laboratory under Contract DE-AC52-07NA27344. 
Carl R. Crawford

DHS S\&T EXD

Csuptwo, LLC

President

8900 N. Bayside Drive

Bayside, WI 53217

414-445-4566

crawford.carl@ csuptwo.com

John S. Beaty

DHS via Awareness and Localization of Explosives-Related Threats

Northeastern University

ALERT Director of Technology Programs

360 Huntington Avenue, 302 Stearns Center

Boston, MA 02115

617-373-5111

jbeaty@coe.neu.edu

David A. Castañón

DHS via Awareness and Localization of Explosives-Related Threats

Boston University

Professor of Electrical \& Computer Engineering

8 Saint Mary's Street

Boston, MA 02215

617-353-9880

dac@bu.edu

Harry E. Martz, Jr. DHS S\&T EXD

Lawrence Livermore National Laboratory Director, Center for Nondestructive Characterization LLNL, L-151, 7000 East Ave.

Livermore, CA 94550

925-423-4269

martz2@1lnl.gov 
Third Party Algorithm Development, Page 4

\begin{abstract}
The US Department of Homeland Security (DHS) has requirements for future explosive detection scanners that include dealing with a larger number of threats, higher probability of detection, lower false alarm rates and lower operating costs. One tactic that DHS is pursuing to achieve these requirements is to augment the capabilities of the established security vendors with third-party algorithm developers. The purposes of this presentation are to review DHS's objectives for involving third parties in the development of advanced algorithms and then to discuss how these objectives are achieved using workshops and grand challenges.
\end{abstract}

Keywords: explosives, detection, aviation, security 
Third Party Algorithm Development, Page 5

\section{Facilitation of Third-party Development of Advanced Algorithms for Explosive Detection Using Workshops and Grand Challenges}

\section{Introduction}

The US Department of Homeland Security (DHS) has requirements for future explosive detection scanners that include dealing with a larger number of threats, higher probability of detection, lower false alarm rates and lower operating costs. One tactic that DHS is pursuing to achieve these requirements is to augment the capabilities of the established security vendors with third-party algorithm developers. A third-party in this context refers to academics, subject matter experts, national laboratories, small companies and organizations other than the established vendors. DHS is particularly interested in adopting the model that has been used very successfully by the medical imaging industry, in which university researchers develop algorithms that are eventually deployed in commercial medical imaging equipment.

One tactic that DHS is using is to sponsor workshops addressing the research opportunities that may enable the development of next-generation algorithms. The first workshop, entitled “Algorithm Development for Security Applications (ADSA) Workshop," was held at Northeastern University (NEU) in conjunction with the DHS Center of Excellence for Awareness and Localization of Explosives-Related Threats (ALERT). A second follow on workshop was held at NEU to discuss the efforts necessary to continue investigation and development of third-party algorithms.

The main recommendation of the first workshop was to establish grand challenges for different aspects of threat detection and different screening modalities. The aspects of threat detection 
Third Party Algorithm Development, Page 6

include reconstruction and processing of sensor data, image segmentation, automated threat detection and improved operator performance. The screening modalities include x-ray computerized tomography (CT) for checked and carry-on baggage, advanced imaging technology, cargo inspection, and stand-off detection.

It was further recommended at the first workshop that the first grand challenge should develop advanced segmentation algorithms from volumetric CT data for the purpose of enhancing automated threat recognition (ATR) algorithms for CT-based scanners. The details of implementing this challenge were discussed at the second workshop. The first phase will entail development, coordination and distribution of data sets, sensor descriptions and acceptance criteria to researchers. These materials will be carefully screened and managed to prevent unintended release of sensitive, proprietary or classified information. The data sets will consist of images of scans of baggage containing known objects. In the second phase, researchers will develop algorithms to segment the objects in the data sets and report their results. The algorithms will be independently graded by ALERT and Lawrence Livermore National Laboratory on other data sets, which will not be provided to the researchers.

A second conclusion from the first workshop was to hold subsequent grand challenges for advanced reconstruction algorithms for CT-based equipment and different aspects of other modalities such as multi-view line scanners (known as advanced technology) and advanced imaging technology, which is also known as whole body imaging. 
The purposes of this presentation are to review DHS's objectives for involving third parties in the development of advanced algorithms and then to discuss how these objectives are achieved using workshops and grand challenges.

\section{Discussion}

\section{State the Problem}

Terrorists still trying and are getting more sophisticated. There is a need to increase the number of smart people working on homeland security.

State the Potential Solution and Research Methodology

Augment the capabilities and capacities of system vendors with third-parties. Third parties can be accessed via workshops and grand challenges.

State the End Users/Customers/Who would benefit

TSA will be able to procure equipment with better performance.

\section{State the Challenges to Attaining the Solution and Results}

TSA is concerned that vulnerabilities will be published. Requirement specifications are classified. Language of homeland security is inaccessible to third-parties. Prizes cannot be given.

\section{Conclusion}

Terrorists still trying and are getting more sophisticated. There is a need to increase the number of smart people working on homeland security. Augmenting capabilities and capacities of system vendors with third-parties is one tactic. Third parties can be accessed via workshops and grand challenges. Successes have been achieved to date. There are issues that need to be resolved to further increase third party involvement. 


\section{References}

Crawford, C. R. (Ed.) (2009). Final Report, Algorithm Development for Security Applications Workshop, Northeastern University, April 23-24, 2009. Report available at: $\mathrm{ftp}: / / \mathrm{ftp}$.censsis.neu.edu/ADSA01.

Crawford, C. R. (Ed.) (2009). Final Report, Algorithm Development for Security Applications Workshop, Northeastern University, October 7-8, 2009. Report available at: $\mathrm{ftp}: / / \mathrm{ftp} . c e n s s i s . n e u . e d u / A D S A 02$.

Crawford, C. R. (Ed.) (2010). Final Report, Algorithm Development for Security Applications Workshop, Northeastern University, April 27-28, 2010. Report available at: $\mathrm{ftp}: / / \mathrm{ftp}$. censsis.neu.edu/ADSA03.

Crawford, C. R. (Ed.) (2010). Final Report, Algorithm Development for Security Applications Workshop, Northeastern University, October 5-6, 2010. Report available at: $\mathrm{ftp}: / / \mathrm{ftp} . c e n s s i s . n e u . e d u / A D S A 04$. 